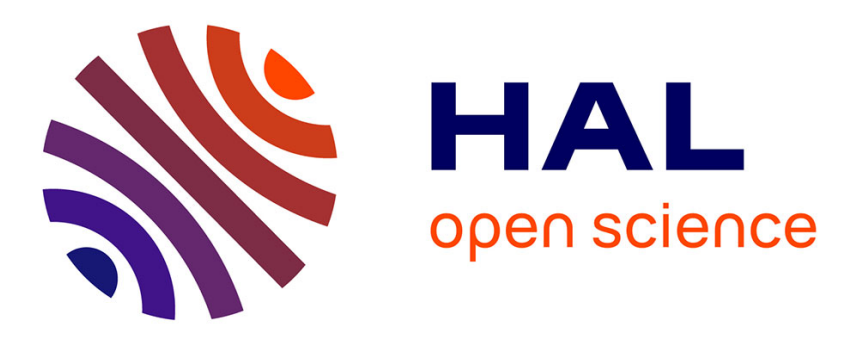

\title{
DyRelA (Dynamic Reliability and Assessment)
}

Gabriel Antonio Perez Castaneda, Jean-François Aubry, Nicolae Brinzei

\section{To cite this version:}

Gabriel Antonio Perez Castaneda, Jean-François Aubry, Nicolae Brinzei. DyRelA (Dynamic Reliability and Assessment). 1st Workshop on DYnamic Aspects in DEpendability Models for FaultTolerant Systems, DYADEM-FTS 2010 in conjunction with European Dependable Computing Conference EDCC 8, Apr 2010, Valence, Spain. pp.39-40. hal-00511378

\section{HAL Id: hal-00511378 \\ https://hal.science/hal-00511378}

Submitted on 24 Aug 2010

HAL is a multi-disciplinary open access archive for the deposit and dissemination of scientific research documents, whether they are published or not. The documents may come from teaching and research institutions in France or abroad, or from public or private research centers.
L'archive ouverte pluridisciplinaire HAL, est destinée au dépôt et à la diffusion de documents scientifiques de niveau recherche, publiés ou non, émanant des établissements d'enseignement et de recherche français ou étrangers, des laboratoires publics ou privés. 


\section{DyRelA (Dynamic Reliability and Assessment) Gabriel A. Pérez Castañeda ${ }^{1,2} \quad$ Jean-François Aubry ${ }^{1} \quad$ Nicolae Brinzei $^{1}$ \\ ${ }^{1}$ CRAN CNRS UMR 7039, Nancy - Université, INPL - ENSEM, \\ 2, avenue de la Forêt de Haye, 54516 Vandoeuvre-lès-Nancy, France \\ ${ }^{2}$ Instituto Tecnológico de Tehuacán, Puebla, México $+33(0) 383595636$ \\ \{perezc76;jean-francois.aubry;nicolae.brinzei\}@ensem.inpl-nancy.fr}

\begin{abstract}
In this paper we present the DyRelA tool designed to perform through a Monte Carlo simulation the assessment of the dependability parameters in the context of dynamic reliability. For that, the studied system is modeled by a stochastic hybrid automaton which has been defined formally. This stochastic hybrid automaton allows taking into account all aspects of the dynamic reliability such as for example the different behaviors of a part under the occurrence of various events. The stochastic hybrid automaton has been implemented in the Scicos toolbox of the Scilab environment. The Monte Carlo simulation is effected by Scilab in batch mode.
\end{abstract}

\section{Keywords}

Dynamic reliability, dependability assessment, hybrid stochastic automaton, Monte Carlo simulation.

\section{INTRODUCTION}

The research of analytical solutions for reliability assessment in dynamic context is not solved in the general case. Partial approaches exist in the case of particular hypothesis. The Monte Carlo simulation would be the only recourse, but there were no efficient tools allowing the simultaneous simulation of the discrete evolution of the system and its continuous evolution taking into account the probabilistic aspects. In this context, we have formally introduced the concept of stochastic hybrid automaton (SHA) which is able of consider all the problems defining the concept of the dynamic reliability:

\footnotetext{
- the dynamic interactions existing between the physical parameters (usually represented by continuous variables) and the nominal or dysfunctional behaviour of the components (usually represented by the occurrence of stochastic events);

- the deterministic or stochastic character of the events and of the physical variables;

- the evolution over time (model reconfiguration) of the reliability structure (indicating how the reliability of the system depends on the reliability of the parts);

- the multiple ageing modes of the components according to the system discrete state;

- the non-binary behaviour of the of the parts;

- the consideration of time instant and occurrence order of the events associated to the discrete state transitions. These events can correspond to component failures or to continuous variables thresholds crossing.
}

So the SHA is able to accede to the assessment of dependability parameters by a Monte Carlo simulation (MCs). Our approach includes notably the consideration of the influence of the discrete state, of the continuous state and their interaction, in the probabilistic assessment of the performances of a system in which besides, the reliability characteristics of components depend themselves on the continuous and discrete states. The stochastic hybrid automaton has been implemented in the Scicos toolbox of the Scilab environment. The Monte Carlo simulation is effected by Scilab in batch mode.

\section{DEFINITION}

$\mathrm{SHA}=\left(X, \mathcal{E}, \mathcal{A}, \mathrm{X}, \mathrm{A}, \mathcal{H}, \mathcal{F}, \mathrm{P}, x_{0}, \mathrm{x}_{0}, \mathrm{P}_{0}\right)$, where $X$ is a finite set of discrete states, $\mathcal{E}$ is a finite set of deterministic or stochastic events, $\mathrm{X}$ is a finite set of real variables evolving in the time. $\mathcal{A}$ is a finite set of arcs of the form $\left(x, e_{j}, \mathrm{G}_{\mathrm{k}}, \mathrm{R}_{\mathrm{k}}, x^{\prime}\right)$ where $x$ and $x$ ' are respectively the origin and goal discrete states of the arc $\mathrm{k}, e_{j}$ is the event associated to this arc, $\mathrm{G}_{\mathrm{k}}$ is the guard condition on $\mathrm{X}$ in the state $x$ and $\mathrm{R}_{\mathrm{k}}$ is the reset function of $\mathrm{X}$ in the state $x^{\prime} . \mathrm{A}$ is a function of activities, $\mathcal{H}$ is a finite set of clocks, $F$ is an application associating each clock to a distribution function, $\mathrm{P}$ is a matrix of probability distributions and $x_{0}, \mathrm{x}_{0}$ et $\mathrm{P}_{0}$ correspond respectively to the initial discrete state, the initial value of the continuous state vector in the discrete initial state and the initial distribution of transition probabilities. The elements $X, \mathcal{E}$ and $\mathcal{A}$ of SHA correspond to the finite state automaton defining its discrete part. In contrast, $\mathrm{X}, \mathrm{A}, \mathrm{R}$ and $\mathrm{G}$ define its continuous part. $\mathcal{H}$ corresponds to its timed aspect and finally $F$ and p express its stochastic aspect. The operating and repair times of parts are materialized by the clock $\mathcal{H}$. These time durations are generated randomly during the simulation from the associated probability distribution functions $F$. For the details of the formal presentation of the SHA see $[1,2]$.

\section{TOOLBOX}

Scilab is a free open-source package for scientific computation. Scicos is one important Scilab toolbox which provides a blockdiagram graphical editor for the construction and simulation of dynamical systems. It is particularly useful for modeling systems where continuous-time and discrete-time components are interconnected [3].

The SHA implementation in the Scicos environment is constituted of three components: an automaton, a mode descriptor and a random generator (figure 1). The automaton is a Scicos block [4] which consists of $n$ input ports (left the block) and two output ports (right the block). The $n$ input ports correspond to the system discrete states. The output port noted " $x, \dot{x}$ " provides the values of continuous state variables $\mathrm{x}$ as well as their derivatives $\dot{\mathrm{x}}$. The output port noted " $x_{i}, x_{i-1}$ " provides the current discrete state of the system as well as the previous one. The output port noted "e" 
(down the block) produces an event when any discrete state transition occurs. By clicking on the automaton block the user can define (on the keyboard) the number of system discrete states, the initial state, the number of continuous state variables as theirs initial values and the different transitions (jump from mode) between discrete states.

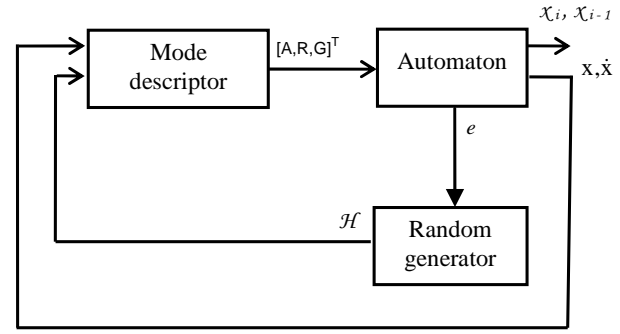

Figure 1. Stochastic hybrid automaton implementation in Scicos environment.

The figure 2 illustrates a part of the implementation in Scicos environment of a dynamic system modeled by the SHA. The system has $X_{n}$ discrete states and $\mathrm{X}_{m}$ continuous state variables. The automaton output ports are two vectors. The first one is of dimension 2 and corresponding to the current and previous discrete states. The second one is of dimension $2 \mathrm{X}_{m}$ and carries the continuous state variables and theirs derivatives.

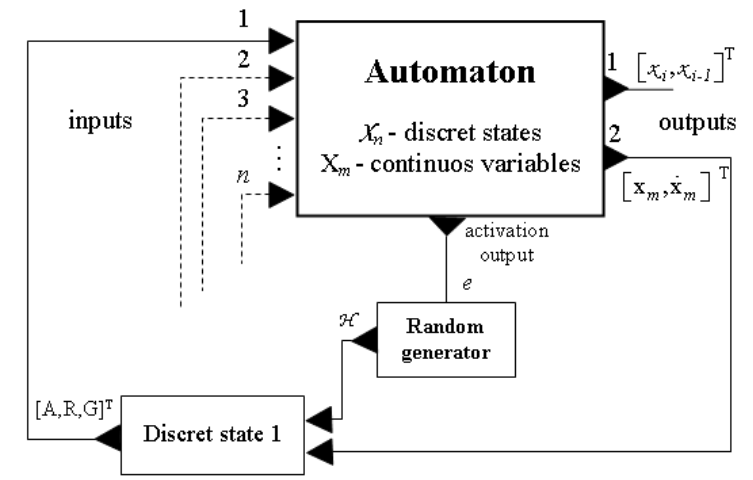

Figure 2. Stochastic hybrid automaton implementation in Scicos environment of a dynamic system.

The mode descriptor block corresponds to the different continuous dynamics of the system. There are as many continuous dynamics as discrete states (or modes). The mode descriptor block has two input ports. The first one coming out of the automaton, which corresponds to the continuous state variables and their derivatives. The second one receives the values produced by the random generator. Each mode is composed by three different Scicos blocks: the first one corresponds to the different system dynamics [A], the second one to the reset values [R] and the third one to the guard conditions [G]. Then the mode descriptor block has $n$ output ports each one defined by the corresponding vector $[A, R, G]^{\mathrm{T}}$.

The random generator is dedicated to the production of the clock structure $\mathcal{H}$. It executes random draws corresponding to the stochastic transitions between current state and potential next ones. Whenever a state transition occurs, the output $e$ of the automaton block generates an event activating the random generator block through its input port (up the block). In the random generator block the user can define the probabilistic laws associated to the stochastic transitions.

For example, we determined by MCs the dependability parameter MTTF (mean time to failure) of the temperature control system of an oven [1]. The system is composed by two loops. The first loop contains a Proportional and Integral controller (PI) whose action is to proportion the thermal energy transmitted to the oven to get the temperature as far as reference value. The second loop is an on-off (ON/F) type one; it keeps the oven temperature around the reference temperature, switching alternately from the full thermal power to a zero power. The two loops can not operate simultaneously. For this, a relay switches the two contacts activating either the PI or the ON/F. The order of switching is given by a detection system whose role is to identify failures and repairs and to react by switching of a regulator to another. At the beginning the oven temperature is controlled by the PI controller. After a random time the controller fails and the oven temperature increases rapidly. The detection system detects that the oven temperature has reached a dangerous value deducing then that the oven temperature is out of control. It gives the order to switch the relay on the ON/F loop. The oven temperature is now controlled by the ON/F. As soon as the detection system has detected an out of control of the temperature starts also the repair process of the PI controller (the reparation is a random time). However, the possibility of the ON/F failure exists. Once the PI controller is repaired the detection system switches the relay on the PI loop controlling the oven temperature. It was considered that the oven is faultless. The SHA of the system is composed by 9 discrete states and one continuous state variable: the temperature. The used computer is a Pentium IV, CPU $3 \mathrm{GHz}$. and 512Kb RAM. The simulation time is $166 \mathrm{sec}$, under the Linux plate-form, with a stop criterion allowing a relative precision of 0.1 with a probability of 0.9 .

\section{REFERENCES}

[1] Pérez Castañeda, G. A. 2009 Évaluation par simulation de la sûreté de fonctionnement de systèmes en contexte dynamique hybride. Thèse Doctorale. Nancy, France, Institut National Polytechnique de Lorraine.

[2] Pérez Castaneda, G. A., Aubry, J.-F. et Brinzei, N. "Modélisation d'un système par automate stochastique hybride pour l'évaluation de la fiabilité dynamique”. Journal européen des systèmes automatisés, pp. 231-255, Volume 44 $\mathrm{N}^{\circ} 2 / 2010$.

[3] Campbell, S. L., Chancelier, J.-P. and Nikoukhah, R. Modeling and Simulation in Scilab/Scicos. Springer. 2006.

[4] Najafi, M. and Nikoukhah, R. "Modeling Hybrid Automata in Scicos”, Multi-conference on Systems and Control (MSC), Singapore, 1-3 October, 2007. 